\title{
Variations in Mass and Resistance Due to Accelerated Weathering Effects in Concrete Specimens Used in Low-income Housing
}

\author{
Aurora Martínez-Loaiza ${ }^{1, *}$. María Teresa Sánchez-Medrano² \\ ${ }^{1}$ Faculty of Engineering "Arturo Narro Siller", Autonomous University of Tamaulipas, University Circuit, South University \\ Center, Tampico, Tamaulipas, Mexico \\ ${ }^{2}$ Faculty of Architecture, Design and Urbanism, Autonomous University of Tamaulipas. University Circuit, South University \\ Center, Tampico, Tamaulipas, Mexico
}

Received August 8, 2020; Revised October 9, 2020; Accepted October 19, 2020

\section{Cite This Paper in the following Citation Styles}

(a): [1] Aurora Martínez-Loaiza. María Teresa Sánchez-Medrano , "Variations in Mass and Resistance Due to Accelerated Weathering Effects in Concrete Specimens Used in Low-income Housing," Civil Engineering and Architecture, Vol. 8, No. 5, pp. 1039 - 1046, 2020. DOI: 10.13189/cea.2020.080530.

(b): Aurora Martínez-Loaiza. María Teresa Sánchez-Medrano (2020). Variations in Mass and Resistance Due to Accelerated Weathering Effects in Concrete Specimens Used in Low-income Housing. Civil Engineering and Architecture, 8(5), 1039 - 1046. DOI: 10.13189/cea.2020.080530.

Copyright $₫ 2020$ by authors, all rights reserved. Authors agree that this article remains permanently open access under the terms of the Creative Commons Attribution License 4.0 International License

\begin{abstract}
The reinforced concrete used for construction represents one of the most widely used materials in urban housing. In the case of coastal areas such as Tampico, Tamaulipas, Mexico, the behavior of the concrete elements used in housing differs from less aggressive environmental areas, as evidenced by the built heritage. This work presents results in relation to causes-effects of environmental loads such as humidity, temperature, solar radiation, acid rain and carbonation on specimens of hardened concrete with f'c of 20 and $25 \mathrm{MPa}$, especially in aspects such as variations in mass and durability and even decreased early resistance. The tested specimens show a variety of relationships that illustrate the effect of the studied parameters, before and after being subjected to accelerated weathering tests; additionally, durability aspects were considered on 6 slab models designed and built to microscopically visualize fissures in the exposed faces, registering mechanical resistance through periodic monitoring that is still maintained. The study showed that concrete with f'c of $20 \mathrm{MPa}$ has greater mass losses and advances in the carbonation front after being exposed in an artificial accelerated aging chamber (AAA), as well as greater degradation when exposed to sulfuric acid, although with less adhesion of salts.
\end{abstract}

Keywords Acid Rain, Carbonation, Fissures,
Concrete Degradation

\section{Introduction}

Concrete is a material commonly used in construction, due to its mechanical characteristics, its versatility and the geometry it can adopt, however, its durability depends on the environmental characteristics in which it is found. Products have been used to improve its resistance to compression, such as fly ash [1] as a substitute for cement, that also improves workability and $\mathrm{CO}_{2}$ reduction [2] and with a design may improve habitability [3]. To reduce degradation, tests for porosity changes and crystalline changes of the solid medium have been carried out to reduce the permeability to water [4], that may contain substances that degrade the solid. Acids are compounds that can reduce the useful life of concrete because it reacts with carbonates and in turn modifies the resistance [5], which also damage the interface of heterogeneous elements. Other components can modify the behavior of concrete mainly when it is armed with steel [6] that interacts producing corrosion which crystallizes with changes in volume and producing cracks. Studies have been carried 
out to know the effects of carbonation on the durability of concrete and some models to produce the effects on its morphological changes [7] [8] as well as the formation of fissures through which degrading compounds can be introduced and use of some additives [9].

Chlorides are ions that can modify the properties of concrete [10] and can produce salts [11] reducing the useful life mainly with the metals that compose it [12].

Due to the above, it is important to carry out studies according to the environment where the material in question is used, in the most aggressive environments such as the marine environment, these effects are accentuated, requiring a set of additives that reduce degradation [13] that can be used in other abrasive environments, as well as taking advantage of the formation of by-products such as phosphates [14] reducing degradation.

Air components can mix with moisture droplets, which in turn travel through the solid microstructure, increasing interaction, as well as corrosion [15][7].

As an extension of the study about the effect of environmental loads on concrete slabs [16], the aim of this work is to correlate causes-effects of humidity, temperature, solar radiation and acid rain with regard to variations in mass and penetration of the carbonation front, in simple concrete specimens with f'c of 20 and 25 MPA, durability aspects are also considered on 6 slab models designed and built to microscopically visualize fissures on exposed faces, recording mechanical resistance through periodic monitoring which is still maintained.

\section{Experimental Report}

Stage 1.- Three experimental models of roof slabs and their corresponding series of specimens for each type of concrete were designed and built, where compliance with the properties of resistance to simple compression, flexion and capillary absorption was verified. In accordance with Mexican standards NMX-C-083-ONNCCE-2014, 150mm diameter and $300 \mathrm{~mm}$ high compression cylinders were tested, NMX-C-191-ONNCCE-2004 600mm long beams, $150 \mathrm{~mm}$ wide and $150 \mathrm{~mm}$ flexed and NMX-C-504-ONNCCE-2015 cylinders with $100 \mathrm{~mm}$ in diameter and $50 \mathrm{~mm}$ high for capillary absorption.

In the experimental models of slabs, such as those commonly used in social interest housing in the southern coastal area of Tamaulipas, the specifications of the technical standards [17] were applied. The cross section of the slab ribs is $10 \mathrm{~cm}$ wide with a total thickness of $15 \mathrm{~cm}$, the longitudinal reinforcement in both beds with a corrugated rod with a diameter of $9.5 \mathrm{~mm}$ and a minimum yield stress of $42 \mathrm{MPa}$ (42 degree). Under the service conditions for this type of housing, no changes are required by applying NTC-2017.

Stage 2. It consisted of obtaining information to correlate environmental loads such as changes in temperature, humidity, the $\mathrm{pH}$ of precipitation and the concentration of atmospheric pollutants that can generate acid rain with respect to the injuries identified in the pathological process of slabs. For this purpose, the experimental models of slabs were monitored for a period of 18 months and two different accelerated tests were carried out on series of concrete specimens. From the three months of construction of the experimental models of slabs, the behavior of the fissures identified by direct observation was analyzed in three-month intervals.

To that end, grids were drawn on the six exposed surfaces every $20 \mathrm{~cm}$, recording the location of the fissures, the width of each fissure was measured with a graduated transparent mica, a capture with a digital camera of each grid with visible fissures and a capture with a digital microscope of fissures with more than $0.5 \mathrm{~mm}$ wide.

To simulate an accelerated process of the effects of acid rain a concentration of $1 \%$ sulfuric acid $(\mathrm{H} 2 \mathrm{SO} 4)$ was used, this concentration was selected according to the results of Yingwu Zhou et al. 2017 [18], allowing to replicate a simulation environment of concrete eroding. This was used on concrete specimens with the same characteristics as those used for capillary absorption tests, for this, the variation of the masses was determined using a balance with an accuracy of $\pm 0.01 \mathrm{gr}$, a laboratory oven for temperatures of $50^{\circ} \mathrm{C} \pm 2^{\circ} \mathrm{C}$ and desiccators.

Once the initial constant mass of a total of 16 specimens was determined, eight for each type of concrete, they were soaked up to a level of $10 \mathrm{~mm}$ in two different fluids, 6 (3 for each type of concrete) in $\mathrm{H} 2 \mathrm{O}$ as control cylinders and 10 ( 5 for each type of concrete) in $1 \%$ $\mathrm{H} 2 \mathrm{SO} 4$, remaining under these conditions for 90 hours, time in which the solution in the concrete stopped reacting as the sulfuric acid was absorbed, then the specimens were removed from the fluids and placed under drying conditions in the environment.

Subsequently, the surfaces were observed using a photographic camera and a digital microscope at 500x magnification, then proceeding to carry out the oven drying process to obtain the final dry mass. The variation of the mass was obtained by calculating the difference between the constant mass obtained after the test in accordance with the initial constant mass, for each of the specimens in both types of f'c.

The second accelerated test consisted of simulating the environmental conditions of solar radiation, elevated temperature, humidity and dew to determine possible injuries in concrete specimens through a QUV model spray accelerated artificial aging chamber.

The test procedure was carried out on concrete specimens (tablets) obtained from the cutting of $150 \mathrm{~mm} x$ $150 \mathrm{~mm}$ x $500 \mathrm{~mm}$ concrete beams used in bending tests. For the cutting, a Controls model 55-C0210 / BZ universal disc cutting machine was used. 
The tablets obtained were measured with a $0.1 \mathrm{~mm}$ digital Vernier, having an average dimension of $75 \mathrm{~mm} \mathrm{x}$ $150 \mathrm{~mm} \times 10 \mathrm{~mm}$, for conditioning the samples until obtaining a constant mass, a balance with an accuracy of \pm $0.01 \mathrm{gr}$, a laboratory oven for temperatures of $50^{\circ} \mathrm{C} \pm 2^{0} \mathrm{C}$ and desiccators were used.

Eighteen tablets of each type of concrete were placed in the artificial accelerated aging chamber (AAA), distributed in such a way that the end panels that receive the least UV rays were free, according to the manufacturer's recommendations as indicated in the Manual [19] for accelerated weathering cameras for the ASTM G 154 cycle.

The specimens were tested for a period of 180 hours, in which a total of 15 cycles were completed, including the simulation of sunlight using ultraviolet fluorescent lamps (step 1), as well as the effects of ambient humidity, rain and dew through spray and condensation cycles in combination with elevated temperature ranges also reproducing thermal shocks and possible mechanical erosion (steps 2 and 3). The time and number of cycles were selected in accordance to the geometry of the selected probes to show a major carbonation process.

To observe possible lesions on the exposed concrete surface, microscopic photographs (500x) were taken of specimens of both types of concrete tested in an accelerated artificial aging chamber and control specimens [20]. Constant mass values were recorded in each specimen before and after the accelerated test, applying the same formula as in the sulfuric acid resistance test for variation in mass $(\Delta \mathrm{m})$.

To determine the penetration of the carbonation front in concrete tablets previously tested in the accelerated aging chamber and in control tablets according to the protocol described by Galán [21], on a freshly cut area and after having removed the dust on the surface, it is sprayed with a $1 \%$ phenolphthalein solution in alcohol. The tested surface shows a bright pink color if the $\mathrm{pH}$ in the concrete maintains its original value, while there are no change in color in the carbonated areas with a pH below 8 .

The carbonation depth was measured with an accuracy of $0.5 \mathrm{~mm}$ in each of the edges of the tested tablets, taking the average value obtained from the maximum and minimum values in each carbonate front.

From the registration carried out in each of the described tests, the results were analyzed to determine the injuries and to correlate the environmental loads studied and the injuries identified in the pathological process of the slabs.

\section{Results and Discussion}

Figure 1 and Figure 2 show the images of the built slabs and the tablets used for the tests.

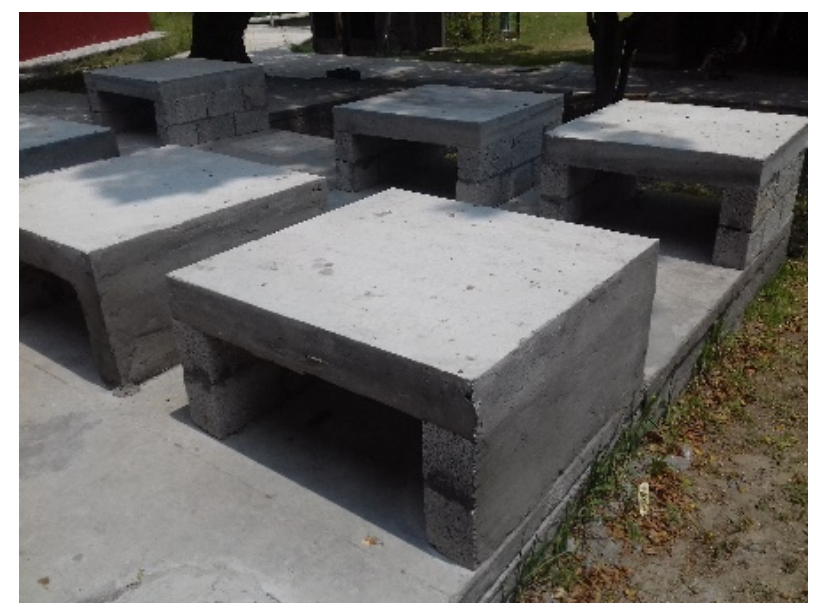

Figure 1. Slabs built as experimental models

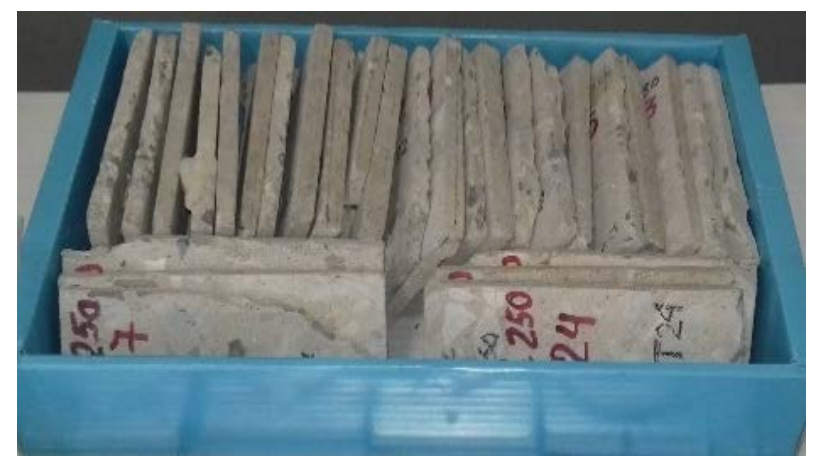

Figure 2. Concrete tablets

In the concrete compressive strength test, the average values obtained experimentally exceed in both cases the specified design resistance, being $19 \%$ in the specimens with $\mathrm{f}^{\prime} \mathrm{c}$ of $20 \mathrm{MPa}$ and $6 \%$ in the specimens with $\mathrm{f}^{\prime} \mathrm{c}$ of $25 \mathrm{MPa}$. It is probable that in the case of specimens with $\mathrm{f}^{\prime} \mathrm{c}$ of $25 \mathrm{MPa}$, the trapped air bubbles have influenced on capillary absorption values in the placement process. A greater capillary absorption is related to the interconnection between the capillary pores of the concrete or with the exterior called open porosity, when this occurs there is a decrease in resistance to the penetration of fluids or an exchange of dissolved substances between the interior of the concrete and the close environment.

From the inspection carried out on the surfaces of the concrete slabs, only contraction fissures were identified that originate from the rapid loss of water on the concrete surface before it sets, and although they are unsightly, they are not usually related to structural damage, however their presence can generate the entry of moisture and the reproduction of microorganisms such as mites over time, which could be observed through the microscope during the measurement process.

This condition can be related more to the construction process than to the design resistances, because the evaporation rates at the surface are affected by the wind speed as well as by the high environmental and concrete 
temperatures; variables that were not controlled, considering that only in the first slab built with a design $\mathrm{f}^{\prime} \mathrm{c}$ of $20 \mathrm{MPa}$ the greatest number of fissures appeared and that in none of the slabs was the width greater than $0.5 \mathrm{~mm}$ throughout the 18-month observation period,

In each of the beams tested in flexion, the failure occurred in the central third, calculating the modulus of rupture with the corresponding equation for this case. The values of the modulus of rupture that express the tensile strength of the concrete in the flexural test represent a range between 10 and $20 \%$ of the compressive strength, a condition that was met in both types of concrete with a value of $12 \%$ in specimens with a design f'c of $20 \mathrm{MPa}$ and $11 \%$ in specimens with a design $\mathrm{f}^{\prime} \mathrm{c}$ of $25 \mathrm{MPa}$.

Table 1. Preliminary tests on concrete specimens

\begin{tabular}{|c|c|c|}
\hline Design value f'c in MPa & 20 & 25 \\
\hline Experimental value f'c in MPa in cylinders & 23.8 & 26.6 \\
\hline Modulus of rupture in MPa in beams & 2.35 & 2.61 \\
\hline Initial absorption speed in $\mathrm{mm} / \mathrm{s} 1 / 2$ & 0.0242 & 0.0242 \\
\hline Initial correlation coefficients & 0.9991 & 0.9995 \\
\hline Secondary absorption speed in $\mathrm{mm} / \mathrm{s} 1 / 2$ & 0.0007 & 0.0009 \\
\hline Secondary correlation coefficients & 0.9861 & 0.9888 \\
\hline
\end{tabular}

The initial rate of absorption in specimens with f'c 20 and $25 \mathrm{MPa}$ presented the same value of $0.0242 \mathrm{~mm} / \mathrm{s} 1$ / 2 and the secondary rate of absorption was $1.28 \%$ higher for specimens with f'c of $25 \mathrm{MPa}$ compared to those of the f'c of $20 \mathrm{MPa}$. The initial and secondary correlation coefficients, being greater than $98 \%$, indicate a linear relationship that validates the results obtained. We saw that linear relationship is higher in the scale required by the Mexican Standard; the concrete absorption curve for the 20MPa samples was $8.52 \pm 0.04 \%$ by weight, having a similar value for those of $25 \mathrm{MPa}$.

Of the six experimental models, only the first slab built with a f'c of $20 \mathrm{MPa}$, called "L-1-200", presented a more irregular surface and contraction fissures with a maximum width of $0.5 \mathrm{~mm}$. In the other slabs, the surfaces were more regular, and the width of their fissures was less than $0.5 \mathrm{~mm}$.

In the observation made over time, no increase in width or new fissures were detected. Figure 3 shows images captured with the microscope at 50x magnification, visualizing the maximum width of fissures detected at three months of age.

Figure 4 shows images captured with the microscope at 50x magnification, nine months after the slabs were made, observing that the widths of the fissures remain unchanged.

Figure 5 shows microscope images captured from the last inspection performed at 18 months of age, showing that the fissure width in the L-1-200 slab remains at $0.5 \mathrm{~mm}$ and in the L-4-250 slab the maximum width of fissures observed is less than $0.5 \mathrm{~mm}$.

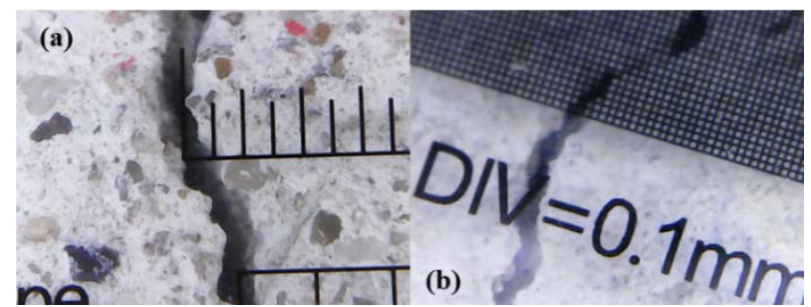

Figure 3. Fissure width in slab "L-1-200" with 3 months of age (50x increase). (a) Ruler with an approximation of $0.5 \mathrm{~mm}$. (b) Mesh with an approximation of $0.1 \mathrm{~mm}$

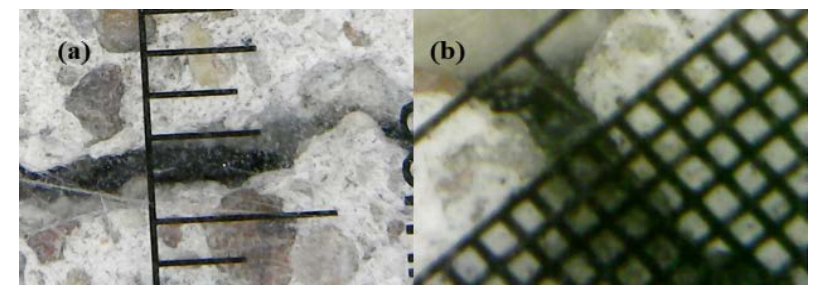

Figure 4. Fissure width in slab "L-1-200" with 9 months of age (50x increase). (a) Ruler with an approximation of $0.5 \mathrm{~mm}$. (b) Mesh with an approximation of $0.1 \mathrm{~mm}$

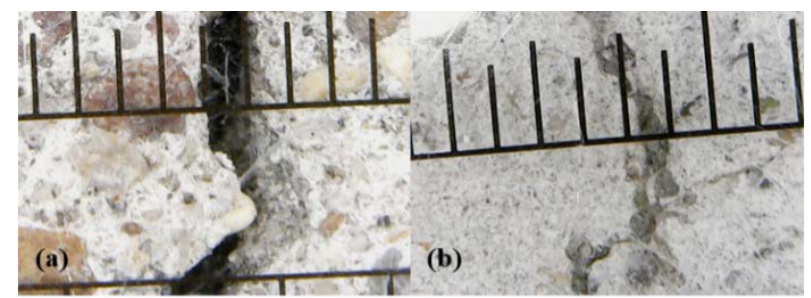

Figure 5. Maximum fissure widths at 18 months of age $(50 \mathrm{x}$ magnification). (a) Slab "L-1-200" and (b) Slab "L-4-250"

Figures 6 show the surfaces captured under a microscope for each type of slab in 50x and 500x magnifications.

In the values obtained in the sclerometer test, the slabs designed with f'c of $20 \mathrm{MPa}$ present values 15\% higher, registering an average resistance $\mathrm{f}^{\prime} \mathrm{c}-\mathrm{i}$ of $23 \mathrm{MPa}$ obtained experimentally, while the slabs with design resistance $f^{\prime} c$ of $25 \mathrm{MPa}$ present the same experimental value f'c-i of 25 MPa.

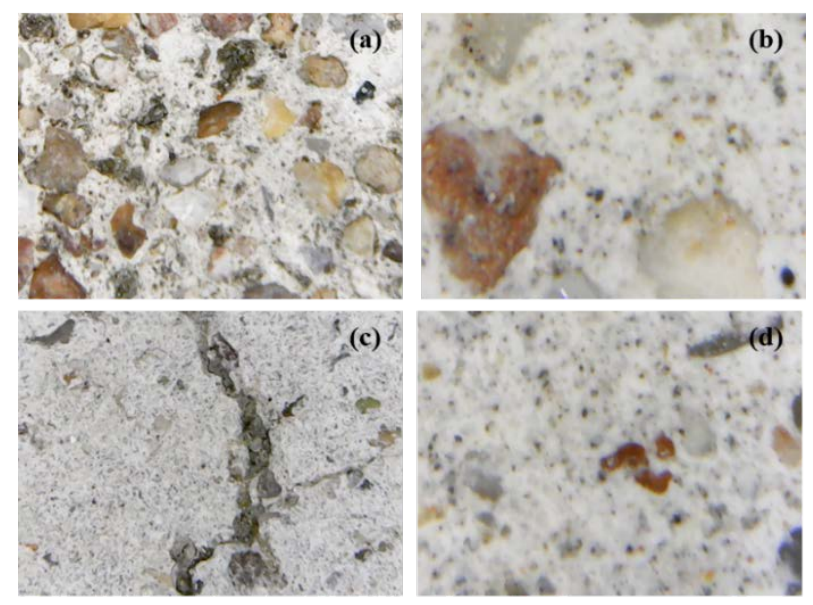

Figure 6. Slab surfaces at 15 months of age, (a) Slab "L-1-200" (50x increase) and (b) Slab "L-1-200 "(increase 500x), (c) Slab" L $-4-250$ ”(50x magnification) and (d)“ L-4-250 "slab (500x magnification). 
Regarding the constant mass values obtained before and after the sulfuric acid resistance test for each type of concrete specimens, they went from $-0.59 \%$ to $0.41 \%$ for those of $20 \mathrm{MPa}$, while those of $25 \mathrm{MPa}$ had a value between $-0.48 \%$. up to $0.61 \%$. From the statistical analysis, it was determined that there is a direct correlation of the mass variations resulting from the sulfuric acid resistance test between the specimens of both concretes.

Regarding the weathering tests, specimens called tablets were obtained from the cutting of concrete beams with a disc cutting machine. The constant mass values obtained before and after the test in the artificial accelerated aging chamber (AAA) in the control tablets for each type of concrete (TC-200 and TC-250) with a loss of mass for 20 and $25 \mathrm{MPa}$ of up to $1.27 \%$ and $0.15 \%$, respectively, due to crumbling, which corresponds to a greater interaction between the components.

Similarly, this process was applied to the tablets tested in the artificial accelerated aging chamber (AAA), they did not present significant differences for a representativeness of up to 25 years with losses of up to $0.69 \%$ and $0.13 \%$ by weight for 20 and $25 \mathrm{MPa}$, respectively, and that are related to the effects of temperature, solar radiation, humidity and dew to which they are exposed (See Table 2). Considering that concrete has components linked by a set of forces that can be modified by energy waves from ultraviolet rays, responsible for the degradation of materials exposed to the elements, the exposure to solar radiation combined with high temperatures and periods of dew and condensation during the accelerated aging test, caused volumetric changes in the concrete tablets and micro-erosion of the exposed surface by crumbling of the concrete due to trapped air bubbles close to the leaking surface of mass, seven times greater in the tablets with $\mathrm{f}^{\prime} \mathrm{c}$ of $20 \mathrm{MPa}$ compared to the tablets of $25 \mathrm{MPa}$.

For the mass variations with the accelerated aging chamber, it was determined that there is a direct correlation of the resulting mass variations between the specimens tested in EAA with $\mathrm{f}^{\prime} \mathrm{c}$ of $20 \mathrm{MPa}$ and those of $f^{\prime} \mathrm{c}$ of $25 \mathrm{MPa}$.

\subsection{Carbonation Potential}

The determination of the carbonation front was performed according to the established protocol applying $1 \%$ phenolphthalein solution in control tablets (CT) and tablets tested in AAA (QT) for each type of concrete, the results of the tested specimens were presented in detail in Martínez and Sánchez [16]. The advance of the carbonation front with $\mathrm{pH}$ values lower than 8 occurs where there is no color change, this condition was recorded in one tablet with $20 \mathrm{MPa} \mathrm{f}^{\prime} \mathrm{c}$ with an average value of $2.5 \mathrm{~mm}$ and in two tablets with $\mathrm{f}^{\prime} \mathrm{c}$ of $25 \mathrm{MPa}$ with an average value of $1 \mathrm{~mm}$ and $3.25 \mathrm{~mm}$. The other control specimens in both types of concrete did not record carbonate areas.

The range of average $\mathrm{CO}_{2}$ penetration values measured in the tablets previously tested in the AAA chamber with $\mathrm{f}^{\prime} \mathrm{c}$ of $20 \mathrm{MPa}$ was between 3 and $5.35 \mathrm{~mm}$ while in the tablets with f'c of $25 \mathrm{MPa}$ it was $3.5 \mathrm{~mm}$ to $7 \mathrm{~mm}$. (See Table 2). This behavior may be related to the interconnection between the pores of the concrete with $\mathrm{f}^{\prime} \mathrm{c}$ of $25 \mathrm{MPa}$, which, even with a lower a / c ratio, presented a higher secondary absorption rate and therefore less resistance to penetration of the carbonation front, generated by subjecting specimens to changes in humidity and high temperatures. Because both types of concrete had injuries related to environmental loads that can lower their strengths, specimens with a design f'c of $20 \mathrm{MPa}$ are more vulnerable. Figure 7 shows the color changes to bright pink on the sprayed surfaces where the $\mathrm{pH}$ retains its value, while on the surfaces where no color change was observed they indicate the advance of the carbonation front with $\mathrm{pH}$ values below 8, You can also observe the measurement process carried out using a graduated mica.

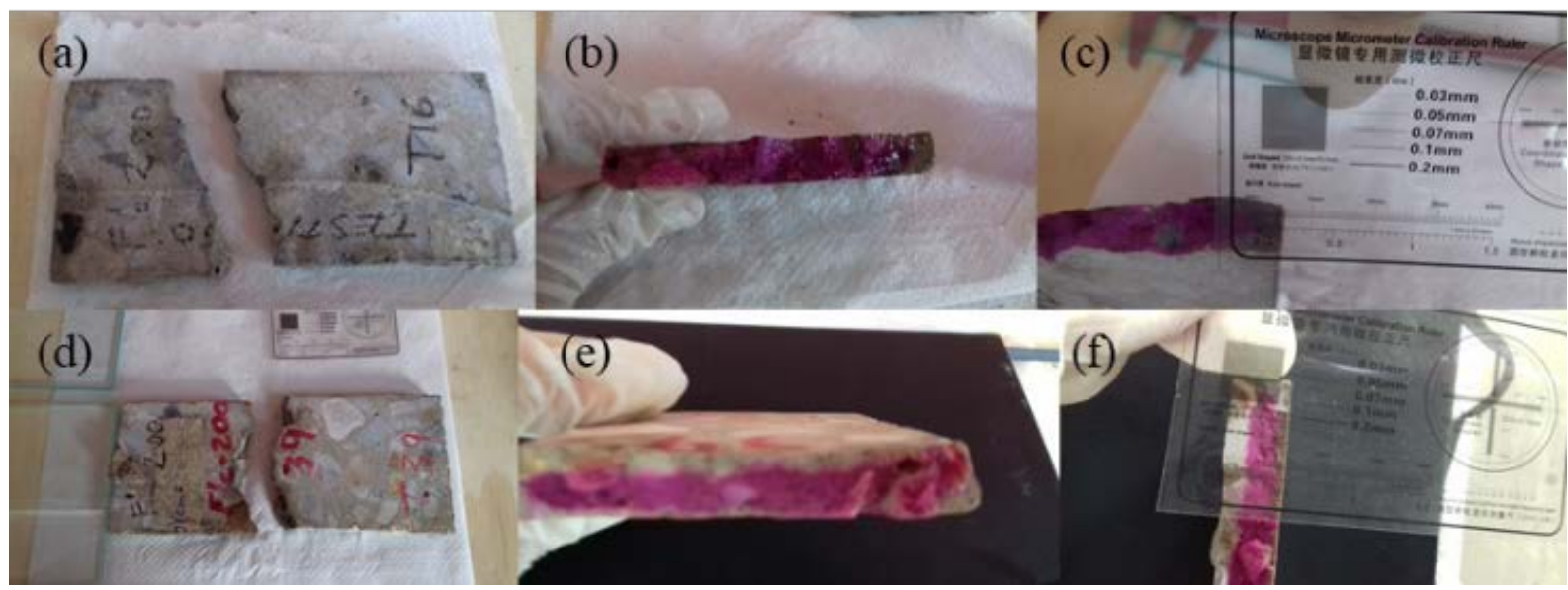

Figure 7. Test to determine the carbonation front with phenolphthalein (a), (b) and (c) Control 25MPa f'c tablet, (d), (e) and (f) 20 MPa f'c tablet from AAA 
Table 2. Injuries to tested specimens of concrete

\begin{tabular}{ccccccc}
\hline \multirow{2}{*}{ Design value f'c } & \multicolumn{2}{c}{ Mass variations by sulfuric acid in $\%$} & \multicolumn{2}{c}{$\begin{array}{c}\text { Mass variations by AAA } \\
\text { chamber in } \%\end{array}$} & \multicolumn{2}{c}{ Carbonation penetration in mm } \\
\hline \multirow{2}{*}{$20 \mathrm{MPa}$} & RAS-20-1 & -0.59 & TQ-20-1 & -0.69 & TQ-20-1 & 3 \\
& RAS-20-2 & -0.28 & TQ-20-2 & -0.13 & TQ-20-2 & 4 \\
& RAS-20-3 & 0.16 & TQ-20-3 & -0.09 & TQ-20-3 & 4.5 \\
& RAS-20-4 & 0.16 & TQ-20-4 & -0.05 & TQ-20-4 & 5.3 \\
& RAS-20-5 & 0.41 & TQ-20-5 & -0.05 & TQ-20-5 & 5.35 \\
& RAS-25-1 & -0.48 & TQ-25-1 & -0.09 & TQ-25-1 & 3.50 \\
& RAS-25-2 & -0.37 & TQ-25-2 & -0.05 & TQ-25-2 & 4.00 \\
& RAS-25-3 & -0.20 & TQ-25-3 & 0 & TQ-25-3 & 4.00 \\
& RAS-25-4 & 0.37 & TQ-25-4 & 0.09 & TQ-25-4 & 5.25 \\
\end{tabular}

From the statistical analysis it was determined that there is a direct correlation between the specimens tested in AAA with $\mathrm{f}^{\prime} \mathrm{c}$ of $20 \mathrm{MPa}$ and those of $\mathrm{f}^{\prime} \mathrm{c}$ of $25 \mathrm{MPa}$ with respect to the carbonation front.

Table 2 shows the lesions determined in each type of concrete specimen tested, such as mass variations by sulfuric acid, mass variations by accelerated aging chamber and carbonation penetration.

Finally, the correlation analysis was performed with Pearson's $r$ having a value of $r=0.87$ with an alpha significance level equal to 0.05 , to accept that there is a correlation between the environmental loads considered in the study and the concrete injuries with resistance to specified compression, f'c of $20 \mathrm{MPa}$ of general use for the elaboration of concrete slabs, and concrete with $\mathrm{f}^{\prime} \mathrm{c}$ of $25 \mathrm{MPa}$ recommended under the durability criteria.

\section{Conclusions}

From the results obtained in the preliminary tests for both types of concrete, it is ruled out that the behavior of each tested specimens is related to poor quality once they met the design specifications. However, it could be noted that the concrete with resistance of design $\mathrm{f}^{\prime} \mathrm{c}$ of $20 \mathrm{MPa}$, experimentally, presented higher values, having as a probable cause the dosage of the mixture, considering that only in the first slab built with a design f'c of $20 \mathrm{MPa}$, the greatest number of fissures appeared, and that in none of the slabs was the width greater than $0.5 \mathrm{~mm}$ throughout the 18-month observation period.

Regarding the behavior of the specimens tested in sulfuric acid, the specimens with f'c of $20 \mathrm{MPa}$ had a $23 \%$ greater degradation and a salt adhesion 67\% less with respect to the specimens with $\mathrm{f}^{\prime} \mathrm{c}$ of $25 \mathrm{MPa}$, being $0.59 \%$ the greatest loss of mass and $0.61 \%$ the greatest increase presented. These conditions denote the reaction processes attributed to the dosage and compounds of the cement. In both cases, the resistances can be affected by modifying the internal structure: by the empty spaces that occurred in degradation or with the increase in mass caused by the formation of salts that occupied a greater space, with respect to the initial components of the concrete, and produce an increase in their volume.

The penetration of the carbonation front for the control tablets of each concrete was null, while there was a decrease in $\mathrm{pH}$ in all the tablets tested in the aging chamber, being $20 \%$ lower than those corresponding to the f'c of $20 \mathrm{MPa}$.

\section{Recommendations}

Although there are studies regarding injuries to structures and there are organisms that have established the measurement of corrosion in reinforced concrete structures related to climatic conditions in various countries, no comparative and correlational studies have been carried out such as those presented in this document. Research work, however, it is necessary to continue making more detailed studies for each type of concrete, as well as a greater knowledge of environmental conditions, using high-tech measurement equipment such as scanning electron microscopy (SEM), infrared spectroscopy (FTIR), solid state nuclear magnetic resonance (MAS-NMR) or nuclear densitometry.

Tests in artificial aging chambers are a useful tool to analyze the behavior of structures, but further studies are required to establish equivalence parameters in camera hours in relation to the age of structures exposed to specific environmental conditions of the area. It is recommended to check the dimensions of the specimens in order to perform mechanical compression tests after exposure in the AAA chamber; case which was not achieved in this study due to equipment limitations.

Although it is true that increasing the resistance index contributes to counteracting injuries, it is not enough to avoid premature deterioration, according to the results that were obtained, it is important to continue proposing an improvement of mix designs that consider modifications 
in cement consumption and possibly the inclusion of additives that improve the physical behavior of concrete structural elements; the handling of additives, the innovation in the cementing are lines that are opened at the end of this investigation, where the regulations clearly show that it cannot be applied in a generalized way, but rather than geographic, climatological and industrialization aspects must be considered in the areas where is built.

\section{Acknowledgements}

Special thanks to Programa para el Desarrollo Profesional Docente (PRODEP; Professional Teaching Development Program), for their support to the publication of this paper.

\section{REFERENCES}

[1] S. A. Shaikuthali, M. A: Mannan, E. T. Dawood, D. C. L. Teo, R. Ahmadi, \& I. Ismail. Workability and compressive strength properties of normal weight concrete using high dosage of fly ash as cement replacement, Journal of Building Pathology and Rehabilitation, Vol.4, No. 26, 2019.

[2] C. Hernandez-Rodriguez, Y. Aranda-Jimenez, Y. \& E. Suarez-Dominguez. The Use of Lime for Carbon Dioxide Production: Brief Analysis, Journal of Scientific Research and Reports, Vol.10, No.4, 1-5, 2016.

[3] I. Amaya-Ruiz C. A. Fuentes-Perez, G. J. Arista-Gonzalez, M. T. Sanchez-Medrano, E. F. Izquierdo-Kulich \& E. J. Suarez-Dominguez. Estimation of the effect of the composition of the wall on the comfort of a building. International Journal, Vol.9, No.3, 1-4, 2020.

[4] V. Cappellesso, N. dos Santos Petry, D. Dal Molin \& A. Masuero. Use of crystalline waterproofing to reduce capillary porosity in concrete. Journal of Building Pathology and Rehabilitation, Vol.1, No.1, 2016.

[5] S. A. Hadigheh, R. J. Gravina\& S. Smith. Effect of acid attack on FRP-to-concrete bonded interfaces. Construction and Building Materials, Vol.152, 285-303, 2017.

[6] K. A. Olonade. A Review of the Effects of Wastewater on Reinforced Concrete Structures in Nigeria. Nigerian Journal of Technology, Vol.35, No.2, 234-241, 2016.

[7] B. Chinè-Polito, R. Cuevas-Kauffmann, R. Jiménez-Salas, G. Ortiz-Quesada \& G. Pridybailo-Checkan. COrrosión del concreto reforzado y DEgradación de sus propiedades MECánicas (CODE_MEC1): Etapa 1 Estudio experimental y modelación computacional de la carbonatación del concreto. 2018.

[8] P. Benítez, F. Rodrigues, S. Talukdar, S. Gavilán, H. Varum \& E. Spacone. Analysis of correlation between real degradation data and a carbonation model for concrete structures. Cement and Concrete Composites, Vol.95, 247-259, 2019
[9] E. J. Suárez-Dominguez, E. Arvizu-Sánchez, J. F. Pérez-Sánchez \& E. F. Izquierdo-Kulich. Effect of a gelatinous media in concrete setting: I. Changes in Surface Morphology Model. IJMTT, Vol.66, No.5, 160-166, 2020.

[10] H. Yu, Y. Tan \& T. Feng, T. Study of temporal change in chloride diffusion coefficient of concrete. ACI Materials Journal, Vol.116, No.1, 103-112, 2019

[11] W. Mazer, A. M. Weber, C. A. Brunhara \& J. M. Fonseca. Salt Attack, Durability and Service Life of Concrete Structures. In: Delgado J. (eds) Building Pathology, Durability and Service Life. Building Pathology and Rehabilitation, Cham (Switzerland): Springer, Vol. 12, 57-72, 2020

[12] C. A. Caldeira Brant, K. Oliveira Coelho, E. Possan, E. Denner, Leonel, \& J. Florez-Lopez. Durability and Service Life Prediction of Reinforced Concrete Frames Subjected to Chloride Corrosion and Mechanical Loading. In Building Pathology, Durability and Service Life. Cham (Switzerland): Springer, pp. 1-39, 2020.

[13] R. F. M. Lima, D. C. dos Santos Lisboa, L. N. Rocha, A. N. Rangel, A. N., C. Gomes de Santana \& R. M. Lobo Muller. Análise do concreto armado em relação à agressividade em ambiente marinho: Estudo comportamental quanto à influência de cloretos da água do mar/Analysis of the reinforced concrete regarding the aggressiveness under marine environment: Behavioral study regarding the influence of the chlorides from the seawater. Brazilian Journal of Development, Vol.6, No.3, 10692-10720, 2020

[14] J. Li, Y. Ji, G. Huang, G., \& L. Zhang. Microstructure Evolution of a Magnesium Phosphate Protective Layer on Concrete Structures in a Sulfate Environment. Coatings, Vol.8, No.4, 140, 2018.

[15] C. A. Bedoya Henao, J. I. Tobón, J. J. Monsalve. Valencia, C. Vanegas Palacio \& M. Valencia Betancur. Evaluación de patologías en el concreto usando microscopía óptica/ Evaluation of pathologies in concrete using optical microscopy. Inf.Téc., Vol. 80, No.2, 142-150, 2016.

[16] A. Martínez Loaiza. y M. T. Sánchez Medrano. Effects on Reinforced Concrete Slabs by Environmental Loads. In International Journal of Innovative Technology and Exploring Engineering (IJITEE). ISSN: 2278-3075, Volume-9 Issue-4, February 2020.

[17] Normas Técnicas Complementarias para Diseño y Construcción de Estructuras de Concreto. Gaceta Oficial de la Ciudad de México, Vigésima época. /Complementary Technical Standards for Design and Construction of Concrete Structures. Official Gazette of Mexico City, Twentieth Period, 220-bis, México, D.F., December 15, 2017. 372-418 On line available from https://www.smig.org.mx/archivos/NTC2017/normas-tecni cas-complementarias-reglamento-construcciones-cdmx-201 7.pdf

[18] Semion Zhutovsky \& R. Douglas Hooton. Accelerated testing of cementitious materials for resistance to physical sulfate attack. Construction and Building Materials, 145, 98-106. 2017

[19] Q-Lab Technical Manual LU-8047-TM Accelerated Weathering Tester Revision Date May 2017

[20] E. J. Suarez-Dominguez, A. Perez-Rivao, M. T. 
Sanchez-Medrano, J. F. Perez-Sanchez \& E. Izquierdo-Kulich. Mesoscopic model for the surface fractal dimension estimation of solid-solid and gas-solid dispersed systems. Surfaces and Interfaces, Vol.18, 100407, 2020.
[21] I. Galán García. Carbonation of concrete: a combination of $\mathrm{CO}_{2}$ with the hydrated phases of the cement and $\mathrm{pH}$ change front. Doctoral thesis. The Complutense University of Madrid. ISBN: 978-84-695-0996-8. 2011. 